\title{
Anti-beta 2 glycoprotein I antibodies in centenarians
}

\author{
P.L. Meroni ${ }^{\mathrm{a}, *}$, D. Mari ${ }^{\mathrm{b}}$, D. Monti ${ }^{\mathrm{c}}$, R. Coppola ${ }^{\mathrm{b}, \mathrm{d}}$, M. Capri ${ }^{\mathrm{e}}$, S. Salvioli ${ }^{\mathrm{e}}$, \\ A. Tincani ${ }^{\mathrm{g}}$, R. Gerli ${ }^{\mathrm{h}}$, C. Franceschi ${ }^{\mathrm{e}, \mathrm{f}}$ \\ ${ }^{a}$ Allergy, Clinical Immunology and Rheumatology Unit, Department of Internal Medicine, University of Milan, IRCCS Istituto Auxologico Italiano, Via G. \\ Spagnoletto 3, 20149 Milan, Italy \\ ${ }^{\mathrm{b}}$ Department of Internal Medicine, University of Milan, IRCCS Ospedale Maggiore, Milan, Italy \\ ${ }^{\mathrm{c}}$ Department of Experimental Pathology and Oncology, University of Florence, Florence, Italy \\ ${ }^{\mathrm{d}}$ Angelo Bianchi Bonomi Hemophilia and Thrombosis Center, IRCCS Ospedale Maggiore, Milan, Italy \\ ${ }^{\mathrm{e}}$ Department of Experimental Pathology, Centro Interdipartimentale "Luigi Galuani”, University of Bologna, Bologna, Italy \\ ${ }_{\mathrm{f}}^{\mathrm{f}}$ Department of Gerontological Research, INRCA, Ancona, Italy \\ ${ }^{\mathrm{g}}$ Clinical Immunology and Rheumatology, Spedali Civili, Brescia, Italy \\ ${ }^{\mathrm{h}}$ Department of Clinical and Experimental Medicine, University of Perugia, Perugia, Italy
}

Received 16 June 2004; received in revised form 5 August 2004; accepted 13 August 2004

Available online 11 September 2004

\begin{abstract}
Background: Non-organ-specific autoantibodies are present in centenarians without evidence of autoimmune diseases but conflicting or no data on anti-phospholipid and anti-phospholipid binding proteins were reported.

Objective: To investigate the presence and antigen specificity of anti-phospholipid and anti-phospholipid binding proteins in centenarians.

Methods: Seventy-seven centenarians, 70 adult controls, 65 unselected elderly subjects, and 38 old SENIEUR volunteers were investigated. Anti-cardiolipin, anti-human $\beta 2$ glycoprotein I, and lupus anticoagulant were detected. Antigen specificity was assayed against plates coated with anionic, neutral and cationic phospholipids and $\beta 2 \mathrm{glycoprotein}$ I-dependence was also evaluated.

Results: $54.3 \%$ of the centenarians were positive for IgG and $8.6 \%$ for IgM anti- $\beta 2$ glycoprotein I antibodies, while only $20.7 \%$ centenarians were positive for anti-cardiolipin IgG and $2.59 \%$ for IgM; none resulted positive for lupus anticoagulant. Anti-cardiolipin positive sera cross-reacted with negatively charged phospholipids and displayed decreased binding to serum-free cardiolipin-coated plates that was restored by human $\beta 2$ glycoprotein I or fetal calf serum.

Conclusions: Centenarians display high reactivity against human $\beta 2$ glycoprotein I but low binding to the bovine molecule in the anticardiolipin assay. In spite of the presence of antibodies comparable to those found in patients with the anti-phospholipid syndrome, no vascular events were reported suggesting the presence of unknown protective factors and/or the lack of triggering factors.
\end{abstract}

(C) 2004 Elsevier Inc. All rights reserved.

\footnotetext{
Abbreviations: aPL, anti-phospholipid antibodies; APS, anti-phospholipid syndrome; LA, lupus anticoagulant; aCL, anti-cardiolipin antibody; B2GPI, $\beta 2$ glycoprotein I; ELISA, solid-phase enzyme-linked immunosorbent assay; PS, phosphatidylserine; PE, phosphatidylethanolamine; PC, phosphatidylcoline; Sph, sphingomyelin; NHS, normal human sera; FCS, fetal calf serum; oxLDL, oxidized LDL; IL, interleukin.

* Corresponding author. Tel.: +39261911 2553; fax: +39261911 2559.

E-mail address: pierluigi.meroni@unimi.it (P.L. Meroni).
}

\section{Introduction}

Centenarians display a characteristic autoantibody profile, being organ-specific autoantibodies absent and non-organ-specific autoantibodies increased without any full-blown autoimmune disease (Mariotti et al., 1992; Candore et al., 1997). In addition, non-organ-specific autoantibodies increase with age, but it is still debated whether aPL are also produced and associated with the clinical manifestations of the APS (Candore et al., 1997; Piette and Cacoub, 1998; Levine et al., 2004). 
Anti-phospholipid antibodies make up a heterogeneous group of autoantibodies diagnosed as LA or aCL, associated with recurrent thrombosis, pregnancy loss, thrombocytopenia and thought to be pathogenic (Levine et al., 2002). Rather than to be directed against PLs only, these antibodies are specific for PL-binding protein (Levine et al., 2002; Meroni and Riboldi, 2001; de Groote et al., 2002; Roubey, 2000). Among them, $\beta 2$ GPI does represent the most important one (de Groote et al., 2002). It has been widely accepted that aCL detectable in APS require the presence of serum PL-binding proteins, mainly $\beta 2 \mathrm{GPI}$, when detected by solid-phase assay (Levine et al., 2002; Meroni and Riboldi, 2001; de Groote et al., 2002; Roubey, 2000). Such an antigen specificity does allow to distinguish them from aPL occurring in infectious diseases which are not usually associated with the clinical manifestations of the syndrome (Levine et al., 2002). In this regard, there is no information on the aPL antigen specificity in centenarians and no data on the occurrence of anti- $\beta 2$ GPI autoantibodies in these subjects (Candore et al., 1997).

Interestingly, centenarians have an increased prevalence of high-risk genetic markers of hypercoagulability (Mari et al., 1995; Mannucci et al., 1997), and are paradoxically characterized by low HDL-cholesterol and relatively high triglyceride levels, which together are considered to be strong risk factors for atherothrombosis (Baggio et al., 1998). It has been suggested that protective mechanisms might counteract these risk factors, allowing them to age successfully and to escape major thrombotic diseases (Baggio et al., 1998).

Taking into account the age-associated immune dysfunction leading to autoimmunity, we investigated the presence of aPL in a total of 250 individuals of different ages, including 77 centenarians. We also characterized the antibodies, in order to assess whether the lack of thrombotic events in these subjects can be related to the antibody antigen specificity or to the paradoxical status that does not induce thrombosis in centenarians in spite of the presence of factors that are risk factors for the general population.

\section{Materials and methods}

\subsection{Subjects and patients}

A total of 250 individuals living in Northern Italy were studied: $n=77$ centenarians [20 males and 57 females, age $102 \pm 1.5$ years (mean $\pm \mathrm{SD}$ ); group 1]; $n=70$ randomly selected, apparently healthy, young control subjects [23 males and 47 females, age 35.8 \pm 9.3 years (group 2)]; $n=65$ unselected elderly subjects [31 males and 34 females, age $70.2 \pm 5.3$ years (group 3)]; and 38 old volunteers [14 males and 24 female, age $70.9 \pm 4.3$ years (group 4)] selected according to the SENIEUR Protocol (Ligthart et al., 1984). Centenarians were selected according to the classification proposed by Franceschi et al. (2000).
APS patients were diagnosed according to the Sapporo's criteria (Wilson et al., 1999).

Approval for these studies were obtained from the Institutional Revue Board of the University of Milan and informed consent was obtained according to Declaration of Helsinki.

\subsection{Anti-phospholipid antibodies}

aCL were detected by ELISA and values expressed as IgG/IgM aPL Units (GPL/MPL, respectively; values were considered positive when $>10$ GPL or MPL) or as low, medium and high positivities as described (Tincani et al., 2001).

Anti-anionic (PS), -neutral (PE, PC), -cationic PL (Sph) activity was evaluated by ELISA as described (Allegri et al., 1990; Tincani et al., 1996; Di Simone et al., 2000).

$\beta 2$ GPI was purified from NHS, and anti- $\beta 2 \mathrm{GPI}$ antibodies were detected by ELISA as described (Tincani et al., 1996; Di Simone et al., 2000; Balestrieri et al., 1995). Sera were considered positive if OD values were higher than the 95 th percentile of 50 normal healthy controls $(0.130$ for $\mathrm{IgG}$ and 0.280 for $\operatorname{IgM}$, respectively).

To evaluate the $\beta 2 \mathrm{GPI}$-dependence of aCL positive sera, aCL assays were performed in the absence of FCS, using gelatin only ( $0.5 \%$; Sigma-Aldrich) in the blocking buffer as well as after addition of human $\beta 2 \mathrm{GPI}(5 \mu \mathrm{g} / \mathrm{ml})$ or FCS (10\%) as described (Di Simone et al., 2000).

\subsection{Lupus anticoagulant}

LA was detected by activated thromboplastin time and by Kaolin clotting time carried out with $0.2 \%$ kaolin suspension in saline (Exner et al., 1978).

\subsection{Statistical analysis}

The association with abnormally high aPL levels were evaluated in logistic regression. Odds ratios and 95\% confidence intervals (CIs) were reported in centenarians, young healthy subjects, unselected elderly subjects and old SENIEUR volunteers.

\section{Results}

\subsection{Prevalence of $a C L$ and $L A$ in centenarians}

Fig. 1 shows the values of IgG (Fig. 1A) and IgM (Fig. 1B) aCL in the different groups. Sixteen out of 77 $(20.7 \%)$ centenarians displayed IgG positivities in comparison to $0 / 70$ in young healthy subjects, $3 / 65(4.6 \%)$ in unselected elderly subjects and $4 / 38(10.5 \%)$ in the old SENIEUR volunteers, respectively. The association with IgG aCL was significantly higher $(p=0.0001)$ in centenarians than in young healthy subjects and in unselected elderly 
A

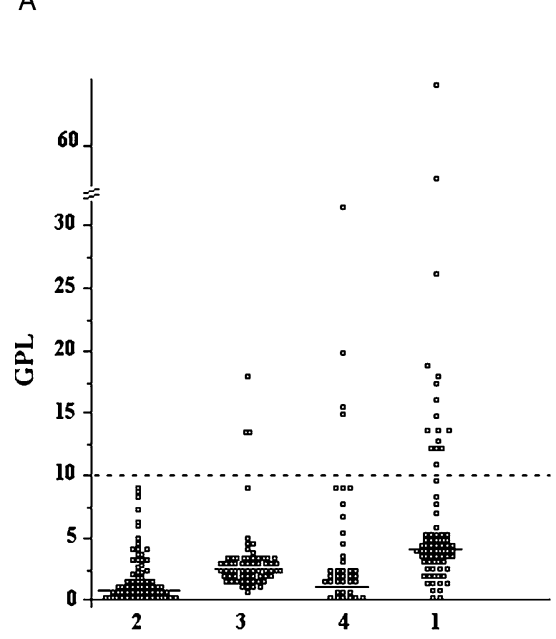

B

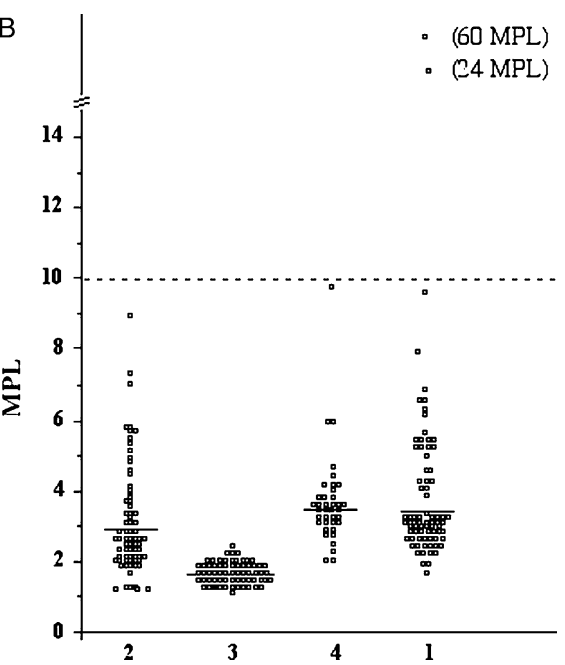

Fig. 1. Prevalence of IgG (A) and IgM (B) aCL in centenarians and control groups: (1) centenarians; (2) healthy young subjects; (3) unselected elderly subjects; (4) old volunteers, selected according to the SENIEUR Protocol (13). The dashed line indicates the cut off limit of normal values; the mean values are represented by horizontal lines. Values are expressed as GPL or MPL units.

subjects $[p=0.01$ (Odds ratio 5.4 CI 95\% 1.5-19.6)] and tended to be higher than in old SENIEUR volunteers $[p=$ 0.140 (Odds ratio 2.4 CI 95\% 0.7-7.7)]. Two samples only from centenarians resulted positive for IgM aCL.

Fifty-nine plasmas were available for LA evaluation and all resulted negative. Ten out of these 59 samples resulted positive in the IgG aCL assay (8/10 low and 2/10 medium positive).

\subsection{Antigen characterization of aCL in centenarians}

Samples positive for IgG aCL from centenarians have been tested against plates coated with PL with different electric charges. Table 1 shows representative results of 10 selected sera (six positive and four negative for IgG aCL) against plates coated with anionic (PS), cationic ( $\mathrm{Sph}$ ) and neutral (PE, PC) PLs. Samples negative for aCL did not display any binding even to plates coated with other anionic PLs. While all the aCL positive sera reacted with negatively
(PS), only few displayed borderline reactivity with neutral (PE, PC) and none with positively (Sph) charged molecules. One serum from centenarians positive also for IgM aCL (24 MPL) displayed a binding activity to PS (0.421 OD value; mean +3 SD of 50 normal controls $=0.198$ OD value). The remaining aCL positive sera from centenarians displayed comparable results (data not shown). As previously reported, sera from APS patients reacted with plates coated with anionic but not with neutral or positive PLs (data not shown) (Di Simone et al., 2000; Harris et al., 1985).

Forty-six sera from centenarians have been tested for anti-human $\beta 2 \mathrm{GPI}$ IgG and IgM antibodies; 25/46 (54.3\%) and $4 / 46(8.6 \%)$ sera, respectively, displayed IgG and IgM anti- $\beta 2$ GPI values higher than the normal controls. Only $4 / 38$ (10.5\%) old SENIEUR volunteers displayed low anti$\beta 2 \mathrm{GPI}$ IgG positivities (lower than 0.320 OD values), while just one unselected elderly subject resulted borderline positive; no positivities for IgM anti- $\beta 2$ GPI antibodies were found (data not shown). Fig. 2 shows the analytical

Table 1

IgG aCL positive sera from centenarians display a cross-reactivity with anionic phospholipids

\begin{tabular}{llllll}
\hline Subject & Anti-CL & $\begin{array}{l}\text { Anti-PS } \\
\text { IgG }\end{array}$ & $\begin{array}{l}\text { Anti-PC } \\
\text { IgG }\end{array}$ & $\begin{array}{l}\text { Anti-PE } \\
\text { IgG }\end{array}$ & $\begin{array}{l}\text { Anti-Sph } \\
\text { IgG }\end{array}$ \\
\hline 1 & & $\mathbf{0 . 9 8 0} \pm \mathbf{0 . 1 5 2}$ & $\mathbf{0 . 2 3 1} \pm \mathbf{0 . 0 2}$ & $\mathbf{0 . 2 0 1} \pm \mathbf{0 . 0 5}$ & $0.001 \pm 0.001$ \\
2 & 97 & $\mathbf{0 . 3 2 4} \pm \mathbf{0 . 1 0 1}$ & $0.041 \pm 0.04$ & $0.05 \pm 0.02$ & $0.021 \pm 0.05$ \\
3 & 12 & $\mathbf{0 . 4 5 2} \pm \mathbf{0 . 1 1 5}$ & $0.092 \pm 0.005$ & $0.06 \pm 0.02$ & $0.034 \pm 0.02$ \\
4 & 19 & $\mathbf{0 . 4 0 2} \pm \mathbf{0 . 1 0 2}$ & $0.045 \pm 0.002$ & $0.101 \pm 0.03$ & $0.025 \pm 0.02$ \\
5 & 16 & $\mathbf{0 . 7 5 8} \pm \mathbf{0 . 1 6 1}$ & $0.157 \pm 0.04$ & $\mathbf{0 . 1 9 7} \pm \mathbf{0 . 0 1}$ & $0.017 \pm 0.01$ \\
6 & 54 & $\mathbf{0 . 2 8 4} \pm \mathbf{0 . 0 2 2}$ & $0.035 \pm 0.03$ & $0.04 \pm 0.03$ & $0.028 \pm 0.01$ \\
7 & 10 & $0.123 \pm 0.098$ & $0.161 \pm 0.054$ & $0.191 \pm 0.045$ & $0.187 \pm 0.052$ \\
8 & 4 & $0.106 \pm 0.047$ & $0.120 \pm 0.085$ & $0.154 \pm 0.074$ & $0.162 \pm 0.068$ \\
9 & 3 & $0.078 \pm 0.021$ & $0.157 \pm 0.079$ & $0.098 \pm 0.021$ & $0.097 \pm 0.031$ \\
10 & 5 & $0.111 \pm 0.075$ & $0.115 \pm 0.073$ & $0.078 \pm 0.052$ & $0.140 \pm 0.075$ \\
\hline
\end{tabular}

Values are expressed in GPL units for aCL and in OD values (mean \pm SD of triplicate experiments) for anti-PS, anti-PC, anti-PE and anti-Sph antibodies. Normal values for anti-PS, anti-PE, anti-PC and anti-Sph antibodies were, respectively, lower than 0.154, 0.194, 0.197, 0.201 (mean +3 SD of 50 normal human sera). Positive results are typed in bold. 


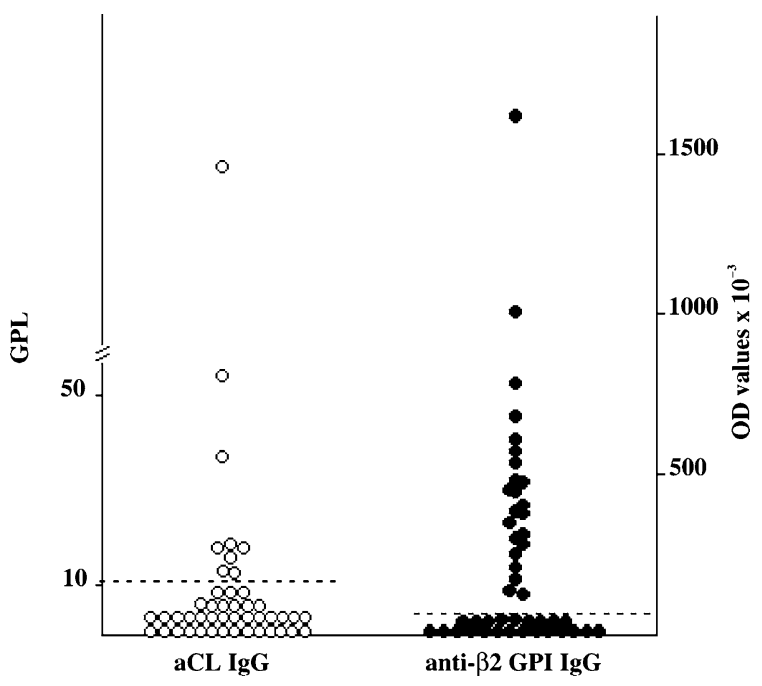

Fig. 2. Anti-cardiolipin and anti-human $\beta 2 \mathrm{GPI}$ IgG antibodies in sera from centenarians. Values are expressed as GPL units or as OD $\times 10^{-3}$ values. The dashed lines indicate the cut off limit of normal values $(10 \mathrm{GPL}$ for aCL and 0.130 OD for anti- $\beta 2$ GPI assay, respectively).
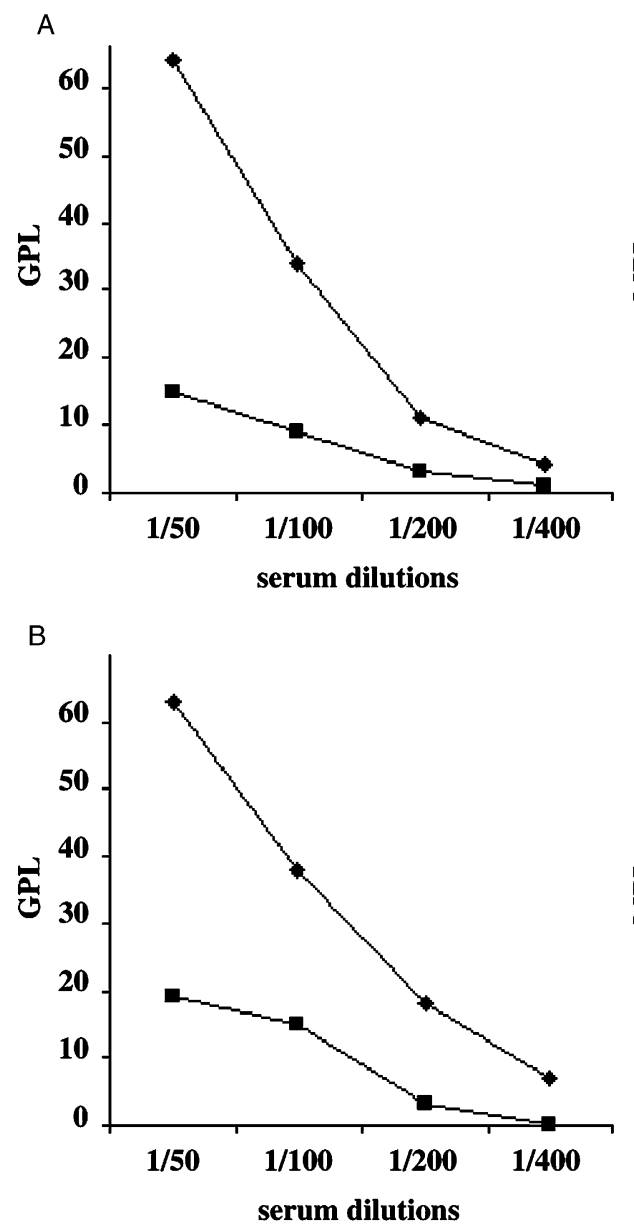

data of anti- $\beta 2 \mathrm{GPI}$ and aCL IgG; interestingly most of the samples reacted with human $\beta 2 \mathrm{GPI}$ but not with CL-coated plates and the reactivity against $\beta 2$ GPI was high in almost half of the samples. Only two out of four IgM anti- $\beta 2$ GPI positive sera also tested positive in the aCL assay (data not shown).

The presence of a reactivity against human $\beta 2 \mathrm{GPI}$ suggests a cofactor dependence for the aCL activity detected in centenarians. In order to demonstrate such a dependence, two positive samples from APS patients or from aCL positive centenarians (two $\operatorname{IgG}$ positive and one IgM positive) were tested with plates blocked with human $\beta 2$ GPI or with gelatin. The binding activity of the sera from centenarians declined when tested on plates without $\beta 2$ GPI (i.e. blocked with gelatin), and the binding was restored by the addition of purified human $\beta 2 \mathrm{GPI}(5 \mu \mathrm{g} / \mathrm{ml})$ in a manner quite comparable to that found with the two APS reference sera. Fig. 3 shows the results of representative samples. Experiments carried out with the addition of FCS (10\%) as source of bovine $\beta 2$ GPI gave comparable results (data not shown).
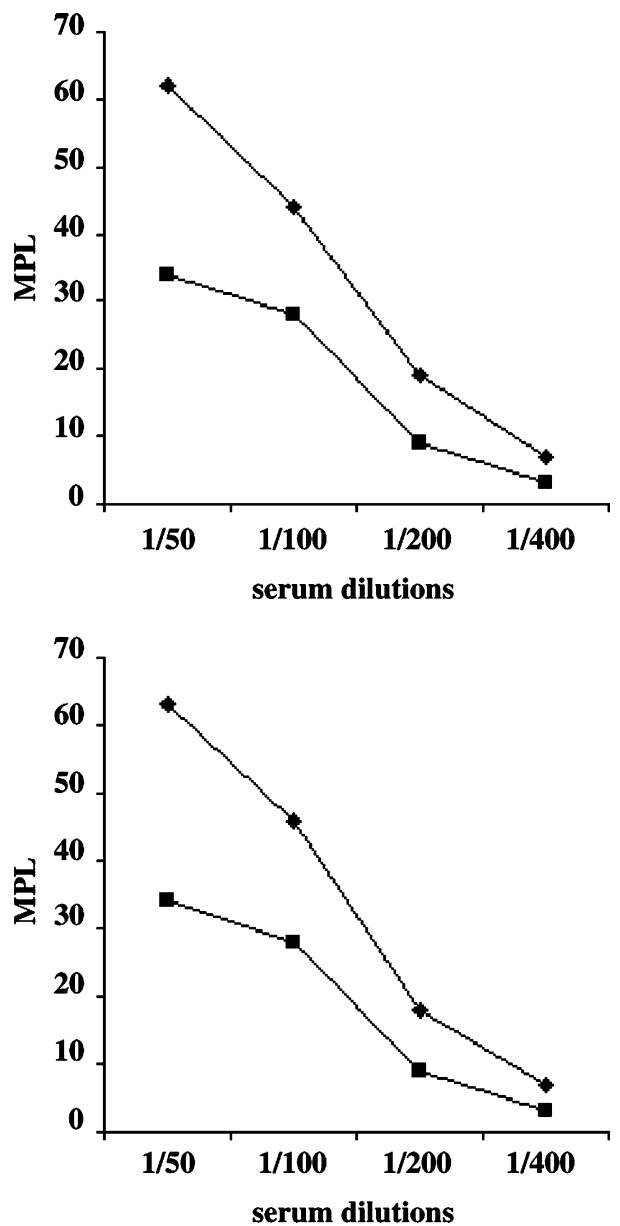

Fig. 3. Beta 2GPI-dependence of IgG and IgM binding to CL-coated plates of representative sera from centenarians (A) and from APS patients (B). Serial dilutions of sera have been tested on serum-free CL-coated plates in the presence $(--)(5 \mu \mathrm{g} / \mathrm{ml})$ or in the absence (-口-) of $\beta 2 \mathrm{GPI}$ as described in Section 2. The values are expressed as GPL or MPL units. 


\section{Discussion}

Our results report for the first time a high prevalence of anti-human $\beta 2 \mathrm{GPI}$ antibodies in centenarians in good health without any clinical manifestation of APS.

Anti- $\beta 2$ GPI antibodies have been recently found to be an apparently more specific, although less sensitive, diagnostic tool for the APS, and to represent an antibody population able to mediate potential pathogenic mechanisms in APS (Levine et al., 2002; Meroni and Riboldi, 2001; Tincani et al., 1998). Moreover, some authors reported that a small but consistent number of patients mirroring a full-blown APS can display antibody against the human $\beta 2$ GPI only, without any cross-reactivity with molecules from other species (Cabral et al., 1996). The lack of reactivity against bovine $\beta 2 \mathrm{GPI}$ was suggested to explain why these patients were negative in the standard assay for aCL antibodies, where bovine $\beta 2$ GPI supplied by FCS is the major target antigen for aPL assay (Levine et al., 2002; Meroni and Riboldi, 2001; de Groote et al., 2002; Roubey, 1999, 2000).

Accordingly, centenarians displayed a high prevalence of antibodies by using human $\beta 2 \mathrm{GPI}$-coated plates but lower prevalence and titres of positive results when the same sera were assayed by the standard aCL assay that employs bovine serum as blocking agent. This finding does suggest that centenarians react with a much more specificity for the human molecule.

It has been widely accepted that aPL detectable in APS display a cross-reactivity with anionic PLs and such a reactivity was suggested to be the result of the binding of the cationic $\beta 2$ GPI to the negatively charged PLs (Roubey, 1999, 2000). Once bound, $\beta 2$ GPI expresses new cryptic epitopes specific for the autoantibodies and/or displays an increased antigen density that is required because of the low affinity of the anti- $\beta 2$ GPI autoantibodies (de Groote et al., 2002; Roubey, 1999, 2000). In line with these findings, a strong reactivity with plates coated with anionic, but negligible with cationic and absent with neutral PLs, was found in sera from centenarians, as reported in APS.

To further support the 'autoimmune' nature of the aPL detectable in our subjects, we investigated whether the aCL positive sera bound to CL-coated plates in a $\beta 2 \mathrm{GPI}$ dependent manner as reported for APS sera. Our data clearly show that the aCL assay carried out in serum-free buffer displayed decreased binding values, and that the reactivity was restored if human purified $\beta 2 \mathrm{GPI}$ or FCS, as source of bovine $\beta 2 \mathrm{GPI}$, were supplied.

Altogether our data suggest that centenarians react preferentially with human $\beta 2$ GPI but that the presence of a cross-reactivity with bovine $\beta 2$ GPI appears to be also responsible for the less frequent positivities in the standard aCL assay.

In the APS, the breakdown of the tolerance towards the self $\beta 2$ GPI has been suggested to be the result of a molecular mimicry between exogenous and self molecules, at least in part due to the wide aminoacid homology of
32GPI from different species (Matsuura et al., 1991; Tincani et al., 2002; Gharavi et al., 1999; Blank et al., 2002). Still debated is the initial trigger of the response against the $\beta 2 \mathrm{GPI}$, although preliminary data suggest that bacterial and/ or viral peptides sharing common aminoacid sequences could be responsible (Gharavi et al., 1999; Blank et al., 2002).

It is useful to speculate on the possible mechanisms that could support the appearance of an anti- $\beta 2$ GPI activity in centenarians. Lifelong exposure to self molecules resulting from the continuous apoptosis occurring in the body, an event particularly consistent in centenarians (Aggarwal and Gupta, 1998), may contribute to this phenomenon. In particular, apoptotic blebs were reported to expose anionic PL (mainly PS) that in turn are able to bind circulating B2GPI (Casciola-Rosen et al., 1996). Such an event results in the exposure of epitopes on the bound molecule that are able to induce an anti- $\beta 2$ GPI humoral immune response in naïve mice (Price et al., 1996). So, it could be possible that the increased exposure of $\beta 2 \mathrm{GPI}$ on apoptotic cells might act as a persistent immunogenic stimulus which could end into an antibody response against the self molecule. Alternatively, it has been also reported that $\beta 2$ GPI bound to oxLDL can be recognized by specific antibodies, suggesting that even in this case, the molecule can display the right immunogenic epitopes (Hasunuma et al., 1997). Furthermore, increased plasma levels of oxLDL have been found in centenarians (Maggi et al., 1993), so offering large amounts of substrates able to bind $\beta 2 \mathrm{GPI}$ and to make the right immunogenic epitopes available to the immune system.

Whatever the mechanisms by which centenarians elicit an anti- $\beta 2$ GPI response comparable to that found in APS, the clinical records of our subjects do not have any evidence of the manifestations associated with the presence of such autoantibodies.

The lack of clinical manifestations might be related to the absence of LA, and to the fact that most of the aCL positive sera in centenarians were at low titre. Actually, it is widely accepted that LA does represent the strongest risk factor for thrombotic events in APS while medium/high aCL titers are closer associated with clinical events than low titres (Levine et al., 2002; Galli et al., 2003). However, such an explanation does not account for the absence of thrombotic events in centenarians with medium or high titres of $\beta 2 \mathrm{GPI}$ dependent aCL.

Anti-phospholipid antibodies are now considered pathogenic autoantibodies rather than a simple serological marker for APS. Several potential mechanisms have been reported to explain the aPL ability to induce thrombosis and/or fetal loss (Meroni and Riboldi, 2001). However, aPL alone apparently are unable to induce thrombotic manifestations per se. In this regard, a two-hit hypothesis has been suggested: aPL (first hit) increases the risk of thrombotic events that occur in the presence of another thrombophilic condition (second hit). In line with such a hypothesis are 
the experimental findings in murine models, in which infusion of aPL can increase clotting after mechanical injury to the vessel wall but do not induce thrombus when injected into uninjured vessels (Pierangeli et al., 2000). Moreover, the two hit hypothesis might also explain why patients persistently positive for aPL do display thrombotic events only occasionally. In this regard, the positivity for aPL with 'autoimmune' characteristics and the concurrent presence of additional risk factors for thrombosis (i.e. hypercoagulability, factor $\mathrm{V}$ mutation, polymorphism $4 \mathrm{G} 4 \mathrm{G}$ of PAI-I promoter, G20210A prothrombin mutation, dyslipidemia) (Mari et al., 1995, 1996; Mannucci et al., 1997; Sacchi et al., 1999; Baggio et al., 1998) in centenarians should favour the appearance of the vascular manifestations of the syndrome. Moreover, we found high plasma levels of pro-inflammatory cytokines, such as IL-6, and low levels of antiinflammatory cytokines, such as IL-10, in centenarians (Bonafè et al., 2001). Pro-inflammatory cytokines might activate monocytes and/or endothelial cells favouring the induction of a pro-coagulant phenotype (Cines et al., 1998; Bouchard and Tracy, 2001) and acting as additional 'second hit' risk factors. Nevertheless, all the subjects of our series escaped major thrombotic diseases. Thus, it is useful to speculate that in centenarians yet unknown mechanisms are active in protecting the thrombophilic state associated to aPL or that in the oldest old, the risk factors could play a different role than in young-adult subjects. Actually, high total cholesterol concentrations have been associated with longevity owing to lower mortality from cancer and infection (Weverling-Rijnsburger et al., 1997).

Further studies aimed to clarify and disentangle such mechanisms could offer new insight to better understand not only the biology of ageing but also the pathophysiology of APS.

\section{Acknowledgements}

This study has been in part supported by Ricerca Corrente IRCCS Istituto Auxologico Italiano 2001/02 (to PLM) and by Progetti di Ricerche Finalizzate, Italian Ministry of Health (to CF and DM), and grants from Italian National Research Council (CNR) to CF.

\section{References}

Aggarwal, S., Gupta, S., 1998. Increased apoptosis of T cell subset in aging humans: altered expression of Fas (CD95), Fas Ligand, Bcl-2, and Bax. J. Immunol. 160, 1627-1637.

Allegri, F., Balestrieri, G., Cattaneo, R., Martinelli, M., Tincani, A., Barcellini, W., 1990. The plasma cofactor and anticardiolipin antibodies. Clin. Exp. Rheumatol. 8, 613-615.

Baggio, G., Donazzan, S., Monti, D., Mari, D., Martini, S., Gabelli, C., Dalla Vestra, M., Previato, L., Guido, M., Pigozzo, S., Cortella, I.,
Crepaldi, G., Franceschi, C., 1998. Lipoprotein(a) and lipoprotein profile in healthy centenarians: a reappraisal of vascular risk factors. FASEB 12, 433-437.

Balestrieri, G., Tincani, A., Spatola, L., Allegri, F., Prati, E., Cattaneo, R., 1995. Anti- $\beta 2$ glycoprotein I antibodies: a marker of antiphospholipid syndrome?. Lupus 4, 122-130.

Blank, M., Krause, I., Shoenfeld, Y., 2002. Molecular mimicry between microbial pathogens and $\beta 2 \mathrm{GPI}$ : induction of experimental antiphospholipid syndrome by passive transfer of anti- $\beta 2 \mathrm{GPI}$ antibodies induced by common bacteria. J. Clin. Invest. 109, 797-804.

Bonafè, M., Olivieri, F., Cavallone, L., Giovagnetti, S., Mayegiani, F., Cardelli, M., Pieri, C., Marra, M., Antonicelli, R., Lisa, R., Rizzo, M.R., Paolisso, G., Monti, D., Franceschi, C., 2001. A gender-dependent genetic predisposition to produce high levels of IL-6 is detrimental for longevity. Eur. J. Immunol. 31, 2357-2361.

Bouchard, B.A., Tracy, P.B., 2001. Platelets, leukocytes, and coagulation. Curr. Opin. Hematol. 8, 263-269.

Cabral, A.R., Amigo, M.C., Cabiedes, J., Alarcon-Segovia, D., 1996. The antiphospholipid/cofactor syndromes: a primary variant with antibodies to beta 2-glycoprotein-I but no antibodies detectable in standard antiphospholipid assays. Am. J. Med. 101, 472-481.

Candore, G., Di Lorenzo, G., Mansueto, P., Melluso, M., Frada, G., Li Vecchi, M., Esposito Pellitteri, M., Drago, A., Di Salvo, A., Caruso, C., 1997. Prevalence of organ-specific and non organ-specific autoantibodies in healthy Centenarians. Mech. Ageing Dev. 94, 183-190.

Casciola-Rosen, L., Rosen, A., Petri, M., Schlissel, M., 1996. Surface blebs on apoptotic cells are sites of enhanced procoagulant activity: implications for coagulation events and antigenic spread in systemic lupus erythematosus. PNAS 93, 1624-1629.

Cines, D.B., Pollak, E.S., Buck, C.A., Loscalzo, J., Zimmerman, G.A., McEver, R.P., Pober, J.S., Wick, T.M., Konkle, B.A., Schwartz, B.S., Barnathan, E.S., McCrae, K.R., Hug, B.A., Schmidt, A.M., Stern, D.M., 1998. Endothelial cells in physiology and in the pathophysiology of vascular disorders. Blood 91, 3527-3561.

de Groote, P.G., Bouma, B., Lutters, B.C.H., Derksen, R.H.W.M., 2002. $\beta_{2-}$ Glycoprotein- 1 and anti $\beta_{2}$-glycoprotein-1 antibodies, in: Asherson, R.A., Cervera, R., Piette, J.C., Shoenfeld, Y. (Eds.), The Antiphospholipid Syndrome II: Autoimmune Thrombosis. Elsevier, Amsterdam, pp. 45-57.

Di Simone, N., Meroni, P.L., Del Papa, N., Raschi, E., Caliandro, D., De Carolis, S., Khamashta, M.A., Atsumi, T., Hughes, G.R., Balestrieri, G., Tincani, A., Casali, P., Caruso, A., 2000. Antiphospholipid antibodies affect trophoblast gonadotropin secretion and invasiveness by binding directly and through adhered $\beta 2$-glycoprotein I. Arthritis Rheum. 43, $140-151$

Exner, T., Rickard, K.A., Kronenberg, H., 1978. A sensitive test demostrating lupus anticoagulant and its behavioural patterns. Br. J. Haematol. 40, 143-151.

Franceschi, C., Motta, L., Valensin, S., Rapisarda, R., Franzone, A., Berardelli, M., Motta, M., Monti, D., Bonafe, M., Ferrucci, L., Deiana, L., Pes, G.M., Carru, C., Desole, M.S., Barbi, C., Sartoni, G., Gemelli, C., Lescai, F., Olivieri, F., Marchegiani, F., Cardelli, M., Cavallone, L., Gueresi, P., Cossarizza, A., Troiano, L., Pini, G., Sansoni, P., Passeri, G., Lisa, R., Spazzafumo, L., Amadio, L., Giunta, S., Stecconi, R., Morresi, R., Viticchi, C., Mattace, R., De Benedictis, G., Baggio, G., the Italian Multicenter Study on Centenarians (IMUSCE), 2000. Do men and women follow different trajectories to reach extreme longevity?. Aging Clin. Exp. Res. 12, 77-84.

Galli, M., Luciani, D., Bertolini, G., Barbui, T., 2003. Lupus anticoagulants are stronger risk factors for thrombosis than anticardiolipin antibodies in the antiphospholipid syndrome: a systematic review of the literature. Blood 101, 1827-1832.

Gharavi, E.E., Chaimovich, H., Cucurullo, E., Celli, C.M., Tang, H., Wilson, W.A., Gharavi, A.E., 1999. Induction of antiphospholipid antibodies by immunization with synthetic viral and bacterial peptides. Lupus 8, 449-455. 
Harris, E.N., Gharavi, A.E., Tincani, A., Chan, J.K., Englert, H., Mantelli, P., Allegro, F., Balestrieri, G., Hughes, G.R., 1985. Crossreactivity of antiphospholipid antibodies. J. Clin. Lab. Immunol. 16, 1-6.

Hasunuma, Y., Matsuura, E., Makita, Z., Katahira, T., Nishi, S., Koike, T. 1997. Involvement of $\beta 2$-glycoprotein I and anti-cardiolipin antibodies in oxidatively modified low density lipoprotein uptake by macrophages. Clin. Exp. Immunol. 107, 569-573.

Levine, J.S., Branch, D.W., Rauch, J., 2002. The antiphospholipid syndrome. N. Engl. J. Med. 346, 752-763.

Levine, S.R., Brey, R.L., Tilley, B.C., Thompson, J.L., Sacco, R.L., Sciacca, R.R., Murphy, A., Lu, Y., Costigan, T.M., Rhine, C., Levin, B., Triplett, D.A., Mohr, J.P., APASS Investigators, 2004. Antiphospholipid antibodies and subsequent thrombo-occlusive events in patients with ischemic stroke. JAMA 291, 576-584.

Ligthart, G.J., Corberand, C.X., Fournier, C., Galanaud, P., Hijmans, W., Kennes, B., Muller-Hermelink, H.K., Steinmann, G.G., 1984. Admission criteria for immunogerontological studies in man: the SENIEUR protocol. Mech. Ageing Dev. 1, 47-55.

Maggi, E., Perani, G., Finardi, G., Franceschi, C., Bellomo, G., 1993. LDL oxidation in aging, in: Corongiu, F., Banni, S., Dessì, M.A., RiceEvans, C. (Eds.), Free Radicals and Antioxidants in Nutrition. Richelieu Press, London, pp. 427-437.

Mannucci, P.M., Mari, D., Merati, G., Tagliabue, L., Sacchi, E., Taioli, E., Sansoni, P., Bertolini, S., Franceschi, C., 1997. Gene polymorphisms predicting high plasma levels of coagulation and fibrinolysis proteins: a study in centenarians. Arterioscler. Thromb. Vasc. Biol. 17, 755-759.

Mari, D., Mannucci, P.M., Coppola, R., Bottasso, B., Bauer, K.A., Rosenberg, R.D., 1995. Hypercoagulability in centenarians: the paradox of successful aging. Blood 85, 3144-3149.

Mari, D., Mannucci, P.M., Duca, F., Bertolini, S., Franceschi, C., 1996. Mutant factor V (Arg506Gln) in healthy centenarians. Lancet 347, 1044.

Mariotti, S., Sansoni, P., Barbesino, G., Caturegli, P., Monti, D., Cossarizza, A., Giacomelli, T., Passeri, G., Fagiolo, U., Pinchera, A., 1992. Thyroid and other organ-specific autoantibodies in healthy centenarians. Lancet 339, 1506-1508.

Matsuura, E., Igarashi, M., Igarashi, Y., Nagae, H., Ichikawa, K., Yasuda, T., Koike, T., 1991. Molecular definition of human $\beta 2$ glycoprotein I by cDNA cloning and inter-species differences of $\beta 2 \mathrm{GPI}$ in alternation of anticardiolipin binding. Int. Immunol. 3, 1217-1221.

Meroni, P.L., Riboldi, P., 2001. Pathogenic mechanisms mediating antiphospholipid syndrome. Curr. Opin. Rheumatol. 13, 377-382.

Pierangeli, S.S., Gharavi, A.E., Harris, E.N., 2000. Experimental thrombosis and antiphospholipid antibodies: new insights. J. Autoimmun. 15, 241-247.
Piette, J.C., Cacoub, P., 1998. Antiphospholipid syndrome in the elderly: caution. Circulation 97, 2195-2196.

Price, B.E., Rauch, J., Shia, M.A., Walsh, M.T., Lieberthal, W., Gilligan, H.M., O’Laughlin, T., Koh, J.S., Levine, J.S., 1996. Antiphospholipid autoantibodies bind to apoptotic, but not viable, thymocytes in a beta 2 -glycoprotein I-dependent manner. J. Immunol. 157, 2201-2208.

Roubey, R.A., 1999. Immunology of the antiphospholipid syndrome: antibodies, antigens, and autoimmune response. Thromb. Haemost. 82, 656-661.

Roubey, R.A., 2000. Antiphospholipid syndrome: antibodies and antigens. Curr. Opin. Hematol. 7, 316-320.

Sacchi, E., Duca, F., Bertolini, S., Franceschi, C., Mari, D., 1999. Prothrombin gene mutation (G20210A) in healthy centenarians. Thromb. Haemost. 81, 990-991.

Tincani, A., Spatola, L., Prati, E., Allegri, F., Ferremi, P., Cattaneo, R., Meroni, P., Balestrieri, G., 1996. The anti- $\beta 2$-glycoprotein I activity in human antiphospholipid syndrome sera is due to monoreactive lowaffinity autoantibodies directed to epitopes located on native $\beta 2$ glycoprotein I and preserved during species evolution. J. Immunol. 157, 5732-5738.

Tincani, A., Balestrieri, G., Spatola, L., Cinquini, M., Meroni, P.L., Roubey, R.A., 1998. Anticardiolipin and anti-beta 2 glycoprotein I immunoassays in the diagnosis of antiphospholipid syndrome. Clin. Exp. Rheumatol. 16, 396-402.

Tincani, A., Allegri, F., Sanmarco, M., Cinquini, M., Taglietti, M., Balestrieri, G., Koike, T., Ichikawa, K., Meroni, P.L., Boffa, M.C., 2001. Anticardiolipin antibody assay: a methodological analysis for a better consensus in routine determinations - a cooperative project of the European Antiphospholipid Forum. Thromb. Haemost. 86, 575-583.

Tincani, A., Gilburd, B., Abu-Shakra, M., Blank, M., Allegri, F., Ottaviani, R., Riboni, M., Meroni, P.L., Balestrieri, G., Shoenfeld, Y., 2002. Immunization of naive BALB/c mice with human beta-2glycoprotein I breaks the tolerance against the murine molecule. Arthritis Rheum. 46, 1339-1404.

Weverling-Rijnsburger, A.W., Blauw, G.J., Lagaay, A.M., Knook, D.L., Meinders, A.E., Westen, R.G., 1997. Total cholesterol and risk of mortality in the oldest old. Lancet 350, 1119-1123.

Wilson, W.A., Gharavi, A.E., Koike, T., Lockshin, M.D., Branch, D.W., Piette, J.C., Brey, R., Derksen, R., Harris, E.N., Hughes, G.R.V., Triplett, D.A., Munther, A., Khamashta, M.A., 1999. International consensus statement on preliminary classification criteria for definite antiphospholipid syndrome: report of an international workshop. Arthritis Rheum. 427, 1309-1311. 